\title{
A odontologia do trabalho como instrumento de prevenção do absenteísmo
}

\author{
Odontology of work as an instrument for the prevention of absentism
}

\author{
Alexandre Ramos Braga" \\ Cirurgião-Dentista, Belo Horizonte, Minas Gerais, Brasil. *Autor para correspondência. E-mail: dr.alexandrebragamg@gmail.com
}

Resumo: Introdução: A saúde do trabalhador conseguiu grandes avanços no Brasil nos últimos anos. A Odontologia do Trabalho aparece para contribuir, pois tem o intuito de estudar, concernir e explanar as diferentes doenças relacionadas a cavidade bucal que acometem os trabalhadores. As doenças bucais não se afastam das condições sistematizadas e não podem ser deixadas de lado quando se contestam as incapacidades que atingem os colaboradores. A implantação do serviço de Odontologia do Trabalho em empresas visando à prevenção da saúde bucal dos colaboradores se faz uma necessidade atual para que associada a medicina do trabalho se vise à integralidade da saúde do trabalhador. A intenção deste estudo foi através de uma análise de literatura discutir o papel do Dentista do Trabalho na prevenção de patologias bucais em trabalhadores e no controle das faltas ao trabalho.

Palavras-chave: colaborador, odontologia do trabalho, prevenção.

\begin{abstract}
Introduction: Worker health has made great strides in Brazil in recent years. Occupational Dentistry is highlighted in this context, as it aims to study, worry and explain the different oral problems that affect workers. Oral diseases do not deviate from systemic conditions and cannot be left aside when discussing disabilities that affect workers. The implementation of the Occupational Dentistry service in companies contains the prevention of workers 'oral health, if there is a current need for associated occupational medicine to aim at the integrality of workers' health. The aim of this work was through a literature review to discuss the role of the Labor Dentist in the prevention of oral pathologies in workers and in the control of absences from work.
\end{abstract}

Keywords: worker, occupational dentistry, prevention.

\section{Introdução}

A política de saúde do trabalhador no Brasil começa a ganhar força na Constituição Federal de 1988, onde a mesma descreve a saúde como um dever do Estado, entendendo que o mesmo através de políticas públicas deve buscar soluções para prover saúde aos cidadãos de forma integral.

A Lei Orgânica da Saúde $n^{\circ}$. 8080/90 também expõe no artigo $6^{\circ}$, parágrafo $3^{\circ}$ que a saúde do Trabalhador como um conjunto de atividades que se destina, por meio de ações de vigilância epidemiológica e sanitária, à promoção e proteção da Saúde do Trabalhador, assim como visa à recuperação e à reabilitação dos trabalhadores submetidos aos riscos e agravos advindos das condições de trabalho".

A boca como entrada do sistema digestivo, em virtude das incumbências que exerce, é uma zona de absorção, retenção e excreção, estando sujeita a agressões de ordem física e química. Por esse ângulo, as condições de trabalho são de notabilidade significativa para as estruturas bucais, podendo ocorrer uma série de anomalias em consequência da exposição de natureza ocupacional (Vianna \& Santanna, 2001).

A Odontologia do Trabalho tem um papel importante na saúde do trabalhador uma vez que as doenças bucais não agem isoladamente e prejudicam e se comunicam com fatores sistêmicos do indivíduo, se tornando parte primordial da medicina do trabalho.

A implantação do serviço de Odontologia do Trabalho em empresas, visando a prevenção da saúde bucal dos trabalhadores, se faz uma necessidade atual para que, associada à medicina do trabalho, se vise a integralidade da saúde do trabalhador.

Essa ferramenta também pode vir de encontro ao controle do absenteísmo, O absenteísmo, de forma genérica, se refere ao distanciamento do colaborador no local de trabalho. Dentre as denominadas ergonomias no processo de trabalho, o absenteísmo se situa entre os efeitos mais nefastos ao processo de trabalho e ao suporte social do colaborador. 
A ausência ao trabalho se configura, nesse sentido, como tendo um duplo resultado: do ponto de vista do trabalhador, a possibilidade de diminuição de renda, do ponto de vista do empregador, a dificuldade de realizar o trabalho previsto e os prejuízos, que porventura, ocorram.

\section{Revisão}

O surgimento da Odontologia do Trabalho, como especialidade, aconteceu com a Resolução do Conselho Federal de Odontologia (CFO) no 22/2001 e 25/2002 (CFO, 2002). Esta resolução estabelece quais as áreas de atuação do cirurgião-dentista especialista.

A Resolução do CFO n 25, de 28 de maio de 2002, definiu as formas de atuação do Odontólogo do Trabalho que incluem a identificação de fatores ambientais que possam trazer prejuízos a saúde bucal do trabalhador, inspeção com relação ao uso de Equipamentos de Proteção Individual, implementar programas de saúde bucal coletivas aos trabalhadores, coletar índices de mortalidade e morbidade dos profissionais e realizar exames admissionais, demissionais e periódicos.(CFO, 2002).

A Resolução 25/2001-CFO define ainda como competência do especialista, a realização de exames odontológicos para fins trabalhistas:

- admissionais: O cirurgião-dentista deve realizar um exame completo do paciente;

- exames periódicos: O cirurgião-dentista deve avaliar o paciente durante o período de permanência na empresa mesmo que não haja dor ou emergências

- retorno ao trabalho: afastamentos acima de 30 dias devem receber uma atenção especial por parte do cirurgião-dentista e receber uma avaliação;

O diagnóstico pregresso das doenças bucais pode denotar um grande avanço no controle do absenteísmo em grandes empresas, tendo em vista que causas odontológicas estão entre os principais motivos de faltas ao trabalho.

Segundo Midorikawa (2000), a Odontologia do Trabalho pode dar grande contribuição para a melhoria da saúde dos colaboradores. O cirurgião-dentista possui conhecimentos sobre a saúde bucal do e é o profissional mais capacitado para ser incorporado a equipe de medicina do trabalho e inspecionar a saúde bucal destes indivíduos.

Vianna e Santana (2001) realizaram uma valiosa revisão de literatura, selecionando oito artigos e uma tese de doutorado. Os resultados são consistentes quando há uma associação entre exposição a névoas ácidas e erosão dental, mais uma vez enfatizando que o cirurgião-dentista é peça fundamental para a equipe de medicina do trabalho.

Segundo Mello (2006), o especialista em Odontologia do Trabalho deve trabalhar em conjunto com os demais profissionais relacionados à saúde do trabalhador. O mesmo deve apresentar soluções que busquem entender a epidemiologia das patologias que acometem os colaboradores e buscar juntamente com os demais membros soluções para melhorar desempenho e qualidade de vida daqueles indivíduos.

Carvalho (2007) realizou um estudo em uma mineradora no noroeste de Minas Gerais, com 662 colaboradores, sobre faltas por motivo de saúde bucal, entre o final de 2006 e início de 2007, realizando um levantamento epidemiológico através do Programa de Controle Médico de Saúde Ocupacional e observou que 39,50\% dos casos de faltas eram por motivos de doenças relacionadas à bucal.

Silva et al. (2010) enfatizou que o cirurgião-dentista é parte determinante da saúde do trabalho como é definido pela lei regulamentadora do Sistema Único de Saúde. A exclusão da saúde bucal do processo de entendimento da medicina do trabalho faz com que se tenha uma perda enorme para a saúde geral do trabalhador.

\section{Discussão}

A implementação de programas de Odontologia do Trabalho em empresas representa um grande avanço à saúde bucal no Brasil e uma grande economia para as empresas, agregando qualidade de vida ao funcionário, evitando não comparecimentos ao labor. As empresas preocupadas com as ausências por motivos odontológicos, passam a investir na promoção de saúde bucal, oferecendo a seus empregados a possibilidade de acesso a tratamento restauradores e preventivos. Com isso os benefícios relatados vão desde a diminuição 
das faltas, a melhoria de condições de saúde e trabalho, até mudança da percepção da empresa por parte do colaborador (Ferreira, 1997).

O absenteísmo é a soma do período em que o trabalhador se ausenta do trabalho. Essas faltas criam diversos problemas, de ordem econômica e social. As licenças de trabalho têm despertado o interesse dos estudiosos uma vez que o seu aumento traz impactos econômicos enormes para as empresas. Dentre as razões para as faltas, chamam bastante atenção as que acontecem por motivo odontológico.

O Brasil tem como característica de sua população a busca por tratamento odontológico somente em casos emergenciais, isso traz um aumento de faltas ao trabalho como também uma diminuição da produtividade do empregado.

O cirurgião-dentista tem como dever diagnosticar e prevenir as doenças que acometem a cavidade oral. Além de diagnosticar o profissional deve analisar epidemiologicamente todo o contexto para entender como tais problemas estão afetando a qualidade de vida do empregado e sua produtividade.

Há necessidade de as entidades representativas competentes continuarem dando ênfase ao esforço que vem desenvolvendo para a construção de bases legais que permitam a atuação do cirurgião-dentista do trabalho na equipe dos Serviços Especializados em Engenharia de Segurança e Medicina do Trabalho (SESMT), em todos os locais que admitem trabalhadores como empregados (empregadores, empresas e instituições), no Programa de Controle Médico de Saúde Ocupacional (PCMSO). O crescimento real da Odontologia do Trabalho no país está diretamente ligado a uma legislação que obrigue as empresas a adotarem o serviço odontológico ocupacional, assim como existe hoje com a Medicina do Trabalho.

\section{Considerações finais}

Apesar de se ter conseguido um grande avanço com a regulamentação da especialidade, a Odontologia do Trabalho só terá uma abrangência maior com a aprovação da PL 422/2007, que trará a obrigatoriedade da inclusão do cirurgião-dentista em empresas e indústrias. A necessidade do cirurgião-dentista se faz presente nas equipes de medicina do trabalho, complementando o trabalho dos médicos do trabalho, enfermeiros e demais profissionais, tratando o indivíduo na sua integralidade. O controle do absenteísmo e do presenteísmo serão benefícios adquiridos pelas empresas com a incorporação da Odontologia do Trabalho.

\section{Referências}

Brasil. Lei no 8080 de 19 de setembro de 1990. Dispõe sobre a organização do SUS. Diário Oficial da União. Brasília: DF.

Brasil. Constituição.1988. Constituição da República Federativa do Brasil. Brasília, DF: Centro Gráfico.

Caetano, J.C. \& Watanabe, A.M. 1994. Noções básicas de odontologia ocupacional para profissionais da saúde do trabalhador. In: Vieira, S. I. Medicina básica do Trabalho. Curitiba: Gênesis.

Carvalho, C. M. 2007. Absenteísmo por causas odontológicas em cooperativa de produtores rurais do estado de Minas Gerais. Belo Horizonte: Associação Brasileira de Odontologia de Minas Gerais.

Conselho Federal de Odontologia. Resolução CFO 25/2002 de 16/05/2002 [acesso 18 jul. 2020]. Disponível em: http://www.cfo.org.br

Conselho Federal de Odontologia. Resolução n ${ }^{\circ} 25$ de 16 de maio de 2002. Estabelece as áreas de competência para atuação dos especialistas em disfunção têmporo-mandibular e dor oro-facial, odontogeriatria, odontologia do trabalho, odontologia para pacientes com necessidades especiais e em ortopedia funcional dos maxilares e dá outras providências. Rio de Janeiro: RJ.

Ferreira, R. A. 1997. Odontologia: essencial para a qualidade de vida. Rev. Assoc. Paul. Cir. Dent.

Garrafa, V. 1986. Odontologia do Trabalho. Ver. Saúde Debate, n.18, p.5-10, mar/abr.

Grativol, K. 2008. Jornada sem fim. Criativa. Rio de Janeiro: Editora Globo.

Mello, P.B.M. 2006. Odontologia do Trabalho Uma visão Multidisciplinar. Rio de Janeiro: Rúbio.

Midorikawa, E. T. 2000. A odontologia como saúde do trabalhador como uma nova especialidade profissional: definição do campo de atuação e funções do cirurgião-dentista na equipe de saúde do trabalhador. Dissertação (Mestrado em Ciências Odontológicas).

Silva, E.S.Bernardo, M.H.; Maeno, M. Kato, M.2010. Saúde do Trabalhador no início do século XXI. São Paulo: SP.

Vianna, M.I. \& Santana, V.S. 2001. Exposição ocupacional a névoas ácidas e alterações bucais: uma revisão. Cad. Saúde Pública. 


\section{Minicurrículo}

Alexandre Ramos Braga. Possui graduação em Odontologia pela Faculdade Newton Paiva. Especialização em Saúde Coletiva pela Faculdade Unyleya, em Ortodontia pela Faculdade Sete Lagoas e em Odontologia do Trabalho pela Faculdade Unyleya.

Como citar: Braga, A.R. 2021. A odontologia do trabalho como instrumento de prevenção do absenteísmo. Pub Saúde, 5, a084. DOI: https://dx.doi.org/10.31533/pubsaude5.a084

Recebido: 5 out. 2020.

Revisado e aceito: 17 out. 2020.

Conflito de interesse: os autores declaram, em relação aos produtos e companhias descritos nesse artigo, não ter interesses associativos, comerciais, de propriedade ou financeiros que representem conflito de interesse.

Licenciamento: Este artigo é publicado na modalidade Acesso Aberto sob a licença Creative Commons Atribuição 4.0 (CC-BY 4.0). 